\title{
Violência contra idosos na cidade do Rio de Janeiro
}

\author{
Violence against the elderly in the city of Rio de Janeiro \\ La violencia contra los ancianos en la ciudad de Río de Janeiro
}

\author{
Edson Alexandre da Silva* \\ Universidade Salgado de Oliveira - Universo, Niterói, Rio de Janeiro, Brasil \\ Lucia Helena de Freitas Pinho França** \\ Universidade Salgado de Oliveira - Universo, Niterói, Rio de Janeiro, Brasil
}

\begin{abstract}
RESUMO
O número de idosos cresceu vertiginosamente, sendo necessárias medidas voltadas para o bem-estar desta população. No tocante à violência contra idosos, há uma carência na investigação das causas e medidas relacionadas à sua prevenção. Esta pesquisa examinou os fatores que influenciam a violência contra idosos na cidade do Rio de Janeiro. A escala de ageísmo de Palmore (2001) foi testada em 284 participantes, com 60 anos ou mais. Foram realizadas análise fatorial, correlações com os preditores e confirmadas por regressão múltipla. Os resultados apontaram que, quanto maior o nível dos conflitos no relacionamento dos idosos, maior será a violência contra eles. Os homens idosos apresentavam maiores conflitos em seus relacionamentos do que as mulheres idosas. Aproximadamente um quarto dos agredidos não denunciam seus agressores, reforçando a tese da subnotificação dos casos. São sugeridas medidas para a redução da discriminação contra idosos.
\end{abstract}

Palavras-chave: violência, idosos, preditores, Rio de Janeiro.

\begin{abstract}
The number of elderly is growing dramatically requiring the implementation of measures for their well-being. There is a lack of research into the causes of violence against the elderly and its prevention. This research examines the factors influencing this violence in the city of Rio de Janeiro. The Palmore Ageism Scale (2001) was tested with 284 participants of 60 yrs or more. Factor analyses and correlations were performed and the predictors confirmed by multiple regression. The results demonstrated that the more intense the level of conflicts in the relationships of the elderly the more frequent the violence suffered by them. Elderly men experienced more intense conflicts in their relationships than elderly women. About a quarter of those who had suffered aggression did not denounce their aggressors, reinforcing the sub-notification of the real number of cases. Measures are suggested for the reduction of discrimination against the elderly.
\end{abstract}

Keywords: violence, elderly, predictors, Rio de Janeiro.

\section{RESUMEN}


El número de personas de la tercera edad ha aumentado de manera espectacular, siendo necesario medidas dirigidas al bienestar de esta población. Con respecto a la violencia contra las personas de edad avanzada, existe una falta de investigación de las causas y las medidas relacionadas con la prevención de la misma. Este estudio examinó los factores que influyen en la violencia contra las personas mayores en la ciudad de Río de Janeiro. La escala de ageísmo de Palmore (2001) se ha probado de 284 participantes, con 60 años o más. Se realizaron análisis factorial, correlaciones con los predictores y confirmada por regresión múltiple. Los resultados mostraron que, a mayor nivel de conflicto en la relación de las personas de edad, los mayores serán los actos de violencia contra ellos. Los ancianos los hombres mostraron mayores conflictos en sus relaciones que las mujeres de más edad. Aproximadamente una cuarta parte de golpeado no denuncian a sus agresores, reforzando la tesis de subregistro de los casos. Se proponen medidas para la reducción de la discriminación contra las personas mayores.

Palavras clave: violencia, ancianos, predictores, Río de Janeiro.

\section{I ntrodução}

Em 1991, a população de brasileiros com 60 anos ou mais era de 10,7 milhões de pessoas (IBGE, 2012). Duas décadas depois, esta população passou mais do que dobrou para 23,5 milhões de idosos. As projeções são de que, em 2025, ou seja, em apenas onze anos, os idosos brasileiros representarão $18 \%$ da população total. Com base nessas projeções, será a primeira vez na história que o número de idosos será maior do que de jovens com até 14 anos (França, 2012). A ciência biomédica e a queda da natalidade corroboram para 0 crescimento da população idosa (Camarano \& Kanso, 2004). Contudo, embora a longevidade seja uma conquista muito relevante para a população, ela, nem sempre, vem acompanhada pela qualidade de vida para os nossos velhos, na medida em que esse envelhecimento populacional traz um lado preocupante: o despreparo da sociedade no trato com esses cidadãos. Alguns estudiosos apontam o indubitável comprometimento da saúde previdenciária (França, 2012; Lima, Wilbert, Pereira \& Paulo, 2012).

A forma vigente de tratamento dispensado aos idosos é tratada por Debert (2004) como a "conspiração do silêncio". A antropóloga justifica seu pensamento por meio de quatro fatores, quais sejam; i) o aumento de gastos com idosos, já que a população idosa cresce mais que a de jovens; ii) a exclusão do velho no capitalismo, já que não se trata mais de mão de obra ativa; iii) o desprezo da cultura brasileira pelas suas tradições, valorizando o jovem e desprezando os velhos; iv) a redução da natalidade em contraposição ao aumento de benefícios assistenciais aos idosos.

Carolino, Cavalcanti e Soares (2010) afirmam que o idoso é considerado inútil depois de esgotadas suas forças de trabalho, da 
mesma forma que Pasinato, Camarano e Machado (2006) apontam para a imagem da obsolescência e improdutividade do idoso dentro do capitalismo. Beauvoir (1990) já ressaltava a perda de qualificação do idoso frente à automação e modernização, ao que Faleiros (2007) responsabiliza a estrutura capitalista excludente, que polariza os recursos e cria um contexto de desigualdades sociais e de discriminação.

A leitura desse cenário parece influenciar a percepção do idoso enquanto um peso social, no sentido de que a influência social nos comportamentos privados exortaria a criação de uma imagem estereotipada. O preconceito é difundido por meio de estereótipos que, conforme Aronson, Wilson e Arket (2002), são observados nas crenças culturais, facilmente reconhecidas pelos membros de determinado grupo. Em outras palavras, surge um "caldo de cultura" que parece trazer uma inclinação à violência (Fonseca \& Gonçalves, 2003).

Como enfatizado por Torres, França, Oliveira \& Presotti (no prelo) o ageismo é a discriminação relacionada à idade, que se manifesta tanto em termos físicos, como cognitivos e sociais, no dia a dia das pessoas mais velhas. A discriminação é formada a partir do exagero ou da omissão de um fato sobre o envelhecimento, onde as características favoráveis do idoso são omitidas ou insuficientemente abordadas, como a crença de que a velhice seja a pior fase da vida das pessoas.

Uma das consequências desse cenário preconceituoso do envelhecimento é a violência. A organização mundial da saúde define a violência como qualquer ação ou omissão que ponha em risco o bem-estar físico ou psicológico, bem como a liberdade e o direito de desenvolvimento pleno (OMS, 2003). No caso do idoso, a violência é um fato atemporal e inerente às várias culturas, cada qual à sua maneira. Sua intensidade e especificidade têm correlação direta com os padrões culturais locais, englobando problemas de gênero, intergeracional e conflitos no seio da família.

Uma revisão bibliográfica sobre violência contra idosos entre 2000 e 2008 realizada por Minayo, Souza e Paula (2010) abrangeu 115 textos, entre artigos, teses e dissertações, monografias e livros existentes. Grande parte dos artigos focalizavam quedas e acidentes com idosos, talvez por conta disso, os autores ressaltaram a relevância da área da saúde pelo impacto que este problema causa a qualidade de vida, embora reconheçam que o tema esteja atraindo atenção da área jurídica e de segurança pública, além dos profissionais do serviço social, fisioterapia, enfermagem e psicologia. Os autores observam ainda que, os primeiros artigos eram mais discursivos visando a sensibilização para o problema, mas a partir de 2003, os textos passaram a dialogar mais com a literatura nacional e internacional, baseando-se no Estatuto do Idoso. 
Outra revisão de literatura sobre o tema (Micheletti, Garcia, Melicchio \& Vagostello, 2011) registrou apenas 28 títulos sobre violência contra idosos, nas bases de dados Scientific Eletronic Library Online (SciELO) e Literatura Latino-Americana e do Caribe em Ciências da Saúde (Lilacs), online entre os anos 2000 e 2008. De acordo com os autores, embora o tema estivesse ganhando popularidade apenas 15 títulos encontravam-se disponíveis para consulta online. A maior parte deles ainda estava concentrada na área da saúde, o que reforça a tese de que a violência contra o idoso é um problema social de saúde pública. Os artigos abordaram as mesmas formas de abuso contra a pessoa idosa: físico, psicológico, sexual, abandono, negligência, financeiro ou econômico e autonegligência.

Castro, Guilam, Souza e Marcondes (2013) em sua revisão de estudos de abordagem qualitativa, entre 2006 e 2011, delinearam três categorias de estudos: i) Construção social e conceituações (vitimas, agressores e cuidadores - 37,5\%); ii) Atenção e Política de Proteção ao Idoso (grupos de pessoas mais vulneráveis e dependentes - 43,75\%); e iii) Tipologia de violência contra idosos (onde a prevalência é a violência física no ambiente domestico $18,75 \%)$. Os estudos analisados evidenciaram que a violência doméstica é a mais frequente contra o idoso.

Algumas pesquisas indicam que a imagem da velhice, como estado decadente e negativo, representa um desejo social de livrar-se do idoso. Em estudo conduzido por Riffiotis (2000), o desejo de extermínio político de idosos foi constatado por um verdadeiro rito em diversas tribos africanas, já que, nessas tribos, as funções sociais etárias são estabelecidas de forma bastante inflexível. Retiradas as suas funções sociais, os idosos são levados a cavernas distantes para morrerem longe de seu povoado (Espíndola \& Blay, 2007; Riffiotis, 2000). De acordo com (Minayo, 2003), o desejo social de morte dos idosos nas sociedades ocidentais se traduz na forma de falta de cuidados básicos pelo cuidador, maus tratos pelos familiares e instituições, conflitos intergeracionais, dentre outras formas de violências.

Fernandes e Assis (1999) descreveram três principais tipos de violência: i) violência física, traduzida pela ofensa à integridade física, como hematomas, queimaduras, fraturas de ossos dentre outras marcas; ii) violência financeira, que se refere à exploração econômica como apreensão de rendimentos, uso ilegal ou ilegítimo de fundos, propriedade e outros ativos dos idosos e iii) violência psicológica, que está relacionada à privação ambiental, social ou verbal; negação de direitos, humilhações, insultos, ofensas, preconceitos e discriminações. Conforme ressaltado por Araujo e Lobo Filho (2009), o abuso psicológico é uma das formas de violência mais difíceis de detectar, porque se processa de forma 
continua silenciosa, favorecendo a desvalorização e impacta na saúde mental do idoso, gerando pânico, distúrbios alimentares e do sono.

Outros tipos de violência são tratados na literatura: uma delas foi a que Pagelow (1984) chamou de negligência. Minayo (2003) complementa esta tipologia com a questão do abandono, a ausência ou deserção no socorro ao ancião dependente de proteção; além da questão do autoabandono ou autonegligência ameaçando à própria por recusa ou insucesso em se autoprover.

Quanto aos fatores de risco, Couto (2005) define como qualquer fato ou ato que forma obstáculo ao nível individual ou ambiental e que predispõe indivíduos a resultados indesejáveis ao seu desenvolvimento. Alguns fatores de risco à violência são abordados pela literatura: Influência sociocultural, condição socioeconômica, sexo, preconceitos, conflitos familiares, subnotificação dos casos, dentre outros.

No presente estudo, os fatores de risco abordados foram: renda familiar, sexo, nível de conflitos e dependência do idoso. No que concerne à renda familiar, determinados autores tecem algumas considerações, senão vejamos: Gonçalves (2006) aponta os escassos recursos econômicos como potencializadores ao risco de violência contra o idoso. Krug (2002) cita a condição econômica como um fator de risco, principalmente quando há abuso de uso de substâncias por parte de jovens na família ou mesmo por indignação do familiar em gastar dinheiro com o idoso. Por outro lado, nem sempre a renda ou condição econômica é preponderante à violência contra idosos (Alencar, 2005; Carneiro \& França, 2011).

$\mathrm{Na}$ questão do sexo enquanto fator de risco, alguns autores apontam as idosas como maiores vítimas de violência em relação aos idosos (Aitken e Griffin, 1996), que associam o risco à opressão e hipossuficiência financeira. Sanches, Lebrão e Duarte (2008) afirmam que as maiores vítimas de violência, no seio familiar, são as mulheres com 80 anos ou mais, submetidas à negligência, duas a três vezes mais do que toda a população idosa. Silva (2011) exemplifica que as mulheres africanas são uma das maiores vítimas, sendo assassinadas pelos mais absurdos motivos, inclusive acusações de feitiçaria. Em estudo conduzido por Sinhoretto (2000) em São Paulo revelou que $57 \%$ das vítimas de violência eram idosas. Em sentido contrário, outros autores entendem que não há diferenças significativas entre vítimas do sexo masculino e feminino (Podnieks, 1992). Pesquisas realizadas no Canadá, nos países baixos e nos Estados Unidos revelaram paridade entre vítimas dos dois sexos (Krug, 2002). No Brasil, Gaioli e Rodrigues (2008) revelaram prevalência de vítimas do sexo masculino.

Quanto ao nível de conflitos familiares, Gaioli e Rodrigues (2008), Vieira, Jacy e Freitas (2005) e Faleiros (2007) apontam uma grande 
incidência de casos de violência decorrentes de relacionamentos conflituosos que podem ocorrer no ambiente familiar. Alves (2004) ressalta que os conflitos conjugais ou familiares são os maiores fatores de risco à violência. Mota (2013) ressalta que os agressores são geralmente filhos e netos das vítimas.

Essas conclusões corroboram as colocações de Faleiros (2007), Valadares e Souza (2010), bem como o estudo conduzido por Gaioli e Rodrigues (2008) que constataram que $87 \%$ dos idosos que participaram da sua pesquisa foram agredidos nas suas próprias residências. Couto, Koller, Novo e Soares (2009) avaliaram 111 pessoas num estudo sobre a discriminação contra idosos utilizandose o Ageism Survey de Palmore (2001). Os autores validaram o Ageism Survey, utilizando a versão de 20 itens adaptada para Portugal (Ferreira-Alves \& Novo, 2006) e apontaram que os tipos de discriminação encontrados estavam relacionados aos contextos sociais e de saúde.

Outro possível preditor de violência contra os idosos foi a dependência dos idosos em relação aos seus cuidadores, mesmo que sejam familiares. Hirsch e Loewy (2001) afirmam que a dependência extrema de idosos para as atividades diárias e o grau de estresse do cuidador podem gerar uma baixa qualidade da relação, que, consequentemente, podem ser considerados fatores de risco de violência contra o idoso. Esta dependência física e cognitiva também são vistas como fatores de risco por Laks, Werner \& Jr. (2006). Contudo, outros defendem que a dependência do idoso não é fator determinante para que ocorram agressões (Cooney, 1995; Paveza, 1992). Debert e Oliveira (2007) afirmam que muitos idosos que sofreram violência eram pessoas ativas, independentes e com renda própria. Estas contradições existentes demonstram a necessidade de serem ampliadas as pesquisas sobre os motivos do aumento da violência contra os idosos.

O objetivo desta pesquisa é o de identificar os fatores que influenciam a violência contra os idosos do Rio de Janeiro. Assim, foram investigados idosos em diversos locais na cidade do Rio de Janeiro. Nesse sentido, esta pesquisa é inédita e apesar de não representar a frequência com que os idosos são agredidos, ouviu os diversos segmentos e aglomerações de idosos, no sentido de identificar os possíveis preditores de violência contra eles.

\section{Método}

Esta pesquisa teve abordagem quantitativa num estudo preditivo e foi realizada com idosos que sofreram ou não violência. Os dados foram coletados por conveniência (não probabilística). Foi realizada inicialmente com idosos do bairro de Copacabana, onde existe a única 
delegacia do idoso da cidade do Rio de Janeiro e, portanto, recebe idosos de diversos bairros. A amostra foi composta, ainda, por idosos residentes em Copacabana, no centro e zona norte do Rio, institucionalizados ou não e que sofreram ou não violência.

\subsection{Participantes}

Participaram desta pesquisa 284 idosos com 60 anos ou mais, vítimas ou não de violência, residentes na zona sul, norte e centro da cidade do Rio de Janeiro (RJ). Foram aplicados 98 questionários na delegacia do Idoso de Copacabana; 86 da Universidade Aberta da Terceira Idade - UNATI; 54 no Abrigo para Moradores de Rua da Prefeitura; 12 no SESC de Copacabana; além de 34 idosos que estavam em praças públicas localizadas na zona sul, norte e centro do RJ.

\subsection{I nstrumentos}

A coleta de dados foi realizada utilizando-se o instrumento Ageism Survey, criado pelo pesquisador americano Palmore (2001), em sua versão original de 20 itens. Os itens do Ageism Survey tratam de estereótipos negativos, atitudes e discriminação pessoal e institucional contra o idoso, medidas em três graus de respostas: (1) nunca ocorreu o episódio; (2) ocorreu uma vez; (3) ocorreu mais de uma vez. Os itens relacionados à violência psicológica nesta escala, por exemplo, são descritos como i) Fui tratado com falta de respeito ou dignidade em razão de minha idade; ii) sofri insulto relacionado à minha idade e iii) Já me disseram algo como você está velho demais para isso.

Foi aplicado ainda um questionário sociodemográfico, com itens relacionados à idade, gênero, profissão, nível de instrução, estado civil, nível de dependência e se sofreu ou não violência nos últimos cinco anos. Os itens foram organizados para a coleta dos dados em diferentes formas tais como: o nome, idade, residência, profissão, tempo de aposentadoria, número de filhos, com quem mora, renda familiar e relato de violência, coletados por meio de respostas escritas nominal ou numericamente. $O$ item sexo foi respondido de forma binária (homem/mulher), já que se trata de variável categórica. O nível de escolaridade comportou opções descendentes, ou seja, pós-graduação, curso superior, 9 a 11 anos, 5 a 8 anos e 0 a 4 anos de educação. $O$ item estado civil trouxe quatro opções de respostas: solteiro (a), separado/divorciado (a), casado/ companheiro (a) ou viúvo (a). O item relacionado à satisfação econômica do participante acomodou cinco opções de resposta: muito satisfatório, satisfatório, nem satisfatório nem insatisfatório, insatisfatório e muito insatisfatório. O grau de dependência geral do idoso foi aferido por uma escala likert ascendente de único item, com 
cinco pontos, em que 1 corresponde a totalmente independente e 5 corresponde a totalmente dependente. A qualidade do relacionamento do idoso com pessoas próximas foi medida pelo nível de conflito percebido pelo participante, numa escala de único item, ascendente com quatro opções de respostas, ou seja: (1) relacionamento sem conflitos (2) com algum conflito (3) com conflitos (4) com muitos conflitos.

\subsection{Procedimentos éticos}

A pesquisa passou pela avaliação do Comitê de Ética da Universidade Salgado de Oliveira (UNIVERSO), sendo aprovada em 30/10/2012 pelo parecer $n^{\circ} 79 / 2012$. As instituições que aceitaram colaborar com a pesquisa cederam dias e horários agendados para a realização do estudo e os participantes assinaram o termo de consentimento livre e esclarecido(TCLE), e receberam orientações acerca do instrumento. O preenchimento do questionário durou aproximadamente dez minutos.

\subsection{Análise de dados}

A análise foi iniciada com a organização e a numeração dos questionários válidos. Em seguida foram lançados os dados coletados no pacote SPSS versão 19 , onde foi efetuada a limpeza do banco de dados para verificar possíveis erros de digitação, bem como a presença de dados omissos (missing values). Alguns erros de digitação foram corrigidos, mas não houve dados omissos.

Foram realizadas análises descritivas, com média e frequência percentual, além de teste $t$, analises fatoriais e regressão linear múltipla. A análise fatorial da Ageism Survey foi efetuada por meio dos componentes principais e rotação varimax Inseriu-se, ainda, nesta análise, a escala unifatorial com três itens referentes à dependência do idoso: dependência econômica, dependência para as atividades diárias e dependência para outras atividades, que resultou no fator denominado dependência geral. Foram efetuadas ainda as correlações de Pearson entre as variáveis; excluiu-se das referidas correlações a variável sexo, testada por meio do teste $t$, com intuito de verificar se havia diferença entre os homens e mulheres idosos quanto à incidência de violência. Por fim, ao efetuar-se o modelo de regressão múltipla, foi acrescentada a variável sexo com a variável dummy $(0=$ feminino; $1=$ masculino $)$ ao inseri-la no modelo de regressão.

\section{Resultados}




\subsection{Analise descritiva}

A amostra foi equilibrada quanto ao sexo (48,9 \% mulheres e $51,1 \%$ homens). A idade dos participantes variou entre 60 e 91 anos, com média de 71 anos. Quanto ao estado civil, 40,5\% eram casados, $21,8 \%$ viúvos (as), $21 \%$ solteiros (as) e $17 \%$ divorciados/separados (as). Cerca de um terço possuía nível superior. Quanto à situação econômica, apenas 38\% declarou rendimentos acima de dois mil reais, que na época representava até quatro salários mínimos. A insatisfação com a situação financeira foi sentida por $42 \%$.

O total de idosos desta pesquisa que admitiu sofrer violência foi de $127(44,7 \%)$ em relação ao total de participantes do estudo ( $\mathrm{N}=$ 284). Contudo, isto não quer dizer que $45 \%$ dos idosos cariocas sofrem de violência. É importante assinalar que dentre os idosos que admitiram ter sido vitima de violência (127), a maior parte foi constituída pelos que estavam na Delegacia do Idoso (98) registrando a ocorrência. Ou seja, retirando-se da amostra total (284 idosos) aqueles que estavam na Delegacia (98 idosos) e que sabidamente sofreram violência, obtêm-se 186 idosos de diversos bairros que sofreram ou não violência. Da mesma forma se forem retirados dos 127 (que admitiram sofrer violência) os 98 (que estavam efetuando queixa na Delegacia), obtêm-se 31 idosos. Assim, o percentual de violência sofrida por idosos nesta nova amostra cairá para 31 idosos, ou seja, $16,7 \%$. Este percentual está bem próximo ao encontrado pela literatura que ressalta que $12 \%$ dos idosos brasileiros já sofreram violência (Gaioli \& Rodrigues, 2008; Vieira, Jacy, \& Freitas, 2005; Faleiros, 2007).

E importante reforçar que o fato de incluir a amostra dos idosos que estavam efetuando denúncia na Delegacia de Idosos de Copacabana que sabidamente sofreram violência - foi muito importante não apenas para que a tipologia de violência no Rio de Janeiro fosse analisada, mas para testar a escala de ageismo de Palmore (2001). Por este motivo foram realizados plantões na Delegacia de Idosos de Copacabana, onde 98 idosos efetuavam denuncias, e aceitaram colaborar com esta pesquisa. Assim, do total de 127 que sofrem de violência, a maior parte dos casos $(51 \%)$ foi provocada por violência psicológica.

As maiores médias de violência sofrida pelos idosos foram encontradas entre aqueles que moravam sozinhos $(M=2,03)$. Entre os que moram acompanhados, a maior média de violência estava entre os que moravam com filhos $(M=1,93)$ e a menor, entre os que moravam com esposos e companheiros $(M=1,48)$. Os idosos institucionalizados sofreram mais violência $(M=1,73)$ do que os não institucionalizados $(M=1,69)$. Apesar de $69 \%$ dos idosos terem prestado queixa na Delegacia, é preocupante o fato de que ainda um 
terço dos idosos violentados não notificaram as autoridades sobre as agressões sofridas.

Os resultados apontaram maior incidência da violência psicológica em relação a outros tipos de violência. Logo a seguir, aparecem os crimes de violência mista, seguida da violência física, e em percentual menor a violência financeira, onde inclui-se empréstimos indevidos em nome dos aposentados pelos familiares. Esta tipologia da violência é apresentada na Tabela 1.

Tabela 1 - Análise descritiva dos tipos de violência pelos idosos que sofreram violência

\begin{tabular}{lrc}
\hline Evento & Frequência & Percentual \\
\hline Violência psicológica & 65 & $51,1 \%$ \\
\hline Violência mista & 38 & $29,9 \%$ \\
\hline Violência física & 16 & $12.8 \%$ \\
\hline Violência financeira & 8 & $6,2 \%$ \\
\hline $\mathrm{N}=127$ participantes que sofreram violência &
\end{tabular}

\subsection{Análise fatorial exploratória da Escala de Ageismo de Palmore}

Inicialmente, foram verificados os pressupostos para a análise fatorial exploratória do Ageism survey (Palmore, 2001) por meio da medida de Kaiser-Meyer-Olkin (KMO), que apresentou resultado igual a 0,75, indicando que as correlações entre os itens permitiam a realização da referida análise, já que Tabachnick e Fidel (2007) consideram como fatorável uma matriz de dados com KMO igual ou superior a 0,60. A matriz de intercorrelações entre os itens foi submetida à análise dos componentes principais, que extraiu sete fatores com valores próprios (eingenvalues) maiores que 1, responsáveis por $63 \%$ da variância total do instrumento. Contudo, vários itens se posicionaram, simultaneamente, em dois ou mais fatores (cross-loadings), ferindo uma das premissas imprescindíveis da análise fatorial, ou seja, a mesma variável não pode contribuir para formar mais de um fator ao mesmo tempo (Hair Black, Babin, Anderson \& Tatham, 2009). Ademais, quando analisadas as variáveis em cotejamento com os fatores a que pertenciam, ocorreram grandes divergências conceituais com os demais itens do fator. Em suma, a extração em sete fatores não foi adequada.

Em seguida, procedeu-se a extração em quatro fatores, com base no eigenvalue $>1$ alcançando uma variância explicada total de 48,72\%. Contudo, persistiram os problemas de bifatoração e incoerência conceitual de alguns itens com o fator.

Seguindo o estudo de Fernandes, Afonso, Pereira e Loureiro (2012), a escala de ageismo foi testada com uma distribuição em três fatores, 
sendo composta por 14 itens com KMO favorável de 0,78. Apresentou um alfa de Cronbach satisfatório $(a=0,80)$ e variância explicada total de $53.76 \%$. Os 14 itens alcançaram cargas fatoriais acima de 0,40 na extração trifatorial, ficando seis itens restantes fora da solução, já que não possuíam cargas fatoriais favoráveis. A distribuição de frequência dos itens é apresentada na Tabela 2 abaixo.

Tabela 2 - Distribuição de frequência dos itens em três fatores

\begin{tabular}{|c|c|c|c|c|}
\hline \\
\hline \multicolumn{5}{|l|}{$\begin{array}{llll}\mathrm{N} & \% & \mathrm{M} & \mathrm{DP}\end{array}$} \\
\hline P3 - Fui ignorado por ser idoso & 74 & 26 & 1,43 & 0,04 \\
\hline P4 - Sofri insulto relacionado à minha idade & 90 & 31,7 & 1,57 & 0,05 \\
\hline $\begin{array}{l}\text { P5 - Já se comunicaram comigo de forma } \\
\text { paternalista }\end{array}$ & 62 & 21,8 & 1,33 & 0,04 \\
\hline $\begin{array}{l}\text { P6 - Alguém já recusou alugar-me imóvel } \\
\text { por eu ser idoso. }\end{array}$ & 15 & 5 & 1,07 & 0,01 \\
\hline $\begin{array}{l}\text { P7 - Tenho dificuldades de obter empréstimo } \\
\text { por ser idoso. }\end{array}$ & 25 & 8,8 & 1,10 & 0,02 \\
\hline $\begin{array}{l}\text { P8 - Negaram-me posição de liderança por } \\
\text { eu ser idoso }\end{array}$ & 6 & 2,1 & 1,04 & 0,02 \\
\hline $\begin{array}{l}\text { P9 - Fui rejeitado como pouco atraente em } \\
\text { razão de minha idade }\end{array}$ & 55 & 19,3 & 1,31 & 0,04 \\
\hline $\begin{array}{l}\text { P10 - Fui tratado com falta de respeito ou } \\
\text { dignidade em razão da minha idade. }\end{array}$ & 105 & 37 & 1,64 & 0,05 \\
\hline $\begin{array}{l}\text { P12 - Medico / enfermeiro atribuíram minhas } \\
\text { dores a idade }\end{array}$ & 51 & 17,9 & 1,24 & 0,03 \\
\hline $\begin{array}{l}\text { P13 - Foi-me negado tratamento médico por } \\
\text { causa da minha idade. }\end{array}$ & 18 & 6,4 & 1,11 & 0,03 \\
\hline $\begin{array}{l}\text { P16 - Já acharam que eu não ouviria bem } \\
\text { por causa de minha idade. }\end{array}$ & 62 & 21,8 & 1,33 & 0,04 \\
\hline $\begin{array}{l}\text { P17 - Já acharam que eu não compreenderia } \\
\text { algo por causa da minha idade. }\end{array}$ & 76 & 26,8 & 1,47 & 0,06 \\
\hline $\begin{array}{l}\text { P18 - Já me disseram algo como você está } \\
\text { velho demais para isso. }\end{array}$ & 84 & 29,5 & 1,43 & 0,04 \\
\hline P20 - Já sofri violência. & 127 & 44,7 & 1,82 & 0,05 \\
\hline
\end{tabular}

Apesar dos dados apresentados serem favoráveis, a decomposição com três fatores apresentou problemas de itens em mais de um fator e conflitos conceituais entre itens e fatores. Assim, resolveu-se adotar a escala como unidimensional tal qual o estudo original (Palmore, 2001). A extração unidimensional resultou em uma escala composta por nove itens, com KMO favorável de 0,83 (vide Tabela 3). A consistência interna foi aferida por meio do alfa de Cronbach satisfatório ( $a=0,84$ ), variância explicada total $45.27 \%$ sendo mantidos os itens com cargas fatoriais superiores a 0,40. Destacamos 
que Pasquali (2012) considera adequadas cargas fatoriais acima de 0,30 .

Tabela 3 - Solução unidimensional do Ageism Survey (Palmore, 2001)

\begin{tabular}{lrr}
\hline Itens do fator & Carga & $\mathbf{h}^{\mathbf{2}}$ \\
\hline (P3) Fui ignorado por ser idoso & 0,72 & 0,52 \\
\hline (P4) Sofri insulto relacionado à minha idade & 0,80 & 0,63 \\
\hline $\begin{array}{l}\text { (P7) Tenho dificuldades de obter empréstimo por eu } \\
\text { ser idoso; }\end{array}$ & 0,43 & 0,18 \\
\hline $\begin{array}{l}\text { (P9) Fui rejeitado como pouco atraente em razão de } \\
\text { minha idade }\end{array}$ & 0,73 & 0,53 \\
\hline $\begin{array}{l}\text { (P10) Tratado com falta de respeito em razão de } \\
\text { minha idade }\end{array}$ & 0,87 & 0,76 \\
\hline $\begin{array}{l}\text { (P16) Acharam que eu não ouviria bem por causa } \\
\text { da minha idade }\end{array}$ & 0,45 & 0,20 \\
\hline $\begin{array}{l}\text { (P18) Já me disseram algo como: você está velho } \\
\text { demais para isso }\end{array}$ & 0,68 & 0,46 \\
\hline $\begin{array}{l}\text { (P19) Minha casa já foi vandalizada por causa da } \\
\text { minha idade }\end{array}$ & 0,45 & 0,20 \\
\hline $\begin{array}{l}\text { (P20) Já sofri violência por minha idade } \\
\text { N= 284; Variância total = 45,26\%; Eigenvalues }=4,07 ; \text { Alfa de }\end{array}$ & 0,57 \\
Cronbach = 0,84
\end{tabular}

\section{Unificação das variáveis correspondentes à dependência do idoso}

Uma escala com três itens foi criada para testar a dependência do idoso: dependência econômica, dependência para as atividades diárias e dependência para outras atividades (ir ao banco, ao cabeleireiro e ao fisioterapeuta) com itens que variavam de 1 a 5 . A medida de Kaiser-Meyer-Olkin (KMO) apresentou resultado igual a 0,60 , indicando que as correlações entre os itens permitiam a realização da análise fatorial. A análise fatorial da escala confirmou sua unifatorialidade, apresentando alfa de Cronbach aceitável ( $a=$ 0,73 ) e $66 \%$ de variância total explicada. As cargas fatoriais foram de 0,45 ou mais.

\section{Correlações de Pearson entre as variáveis do estudo}

Foram procedidas as correlações entre a variável dependente (violência) e as variáveis independentes, exceto o sexo, que foi testado por meio do teste $t$ com intuito de verificar se havia diferença quanto à incidência de violência entre os homens e mulheres mais velhos. Para a interpretação dos resultados foram utilizadas as orientações de Miles e Shevlin (2001), que estabeleceram uma classificação da magnitude dos coeficientes de correlação baseada 
nos seguintes intervalos: $0,10-0,29$ (baixa); $0,30-0,49$ (moderada) e maior que 0,50 (elevada). Nesse contexto, extraíramse os seguintes resultados, que podem ser observados na Tabela 4:

1) A correlação entre violência e nível de conflitos é positiva, moderada e significativa $(r=0,31 ; p<0,001)$.

2) A correlação entre violência e dependência é negativa, baixa e significativa $(r=-0,10 ; p<0,05)$.

3) A correlação entre violência e renda familiar é negativa, baixa e significativa $(r=-0,10 ; p<0,05)$.

Tabela 4 - Matriz de correlações entre as variáveis do estudo

A B C Conflito $\mathbf{D}$ dependência

Violência Renda

\begin{tabular}{lllll}
\hline a. & 1,00 & $-0,10^{*}$ & $0,31^{* * *}$ & $-0,10^{*}$ \\
\hline b. & $0,10^{*}$ & 1,00 & $-0,03$ & $-0,37^{* *}$ \\
\hline c. & $0,31^{* * *}$ & $-0,03$ & 1,00 & $-0,14^{*}$ \\
\hline d. & $0,10^{*}$ & $-0,37^{* * *}$ & $-0,14^{* *}$ & 1,00 \\
\hline $\mathrm{N}=284 ;{ }^{*} \mathrm{p}<0,05 ;{ }^{* *} \mathrm{p}<0,01 ;{ }^{* * *} \mathrm{p}<0,001$.
\end{tabular}

\section{Teste t entre sexos}

Os participantes do sexo masculino alegaram ter sofrido mais eventos de violência $(M=1,50 ; D P=0,54)$ do que os participantes do sexo feminino $(M=1,35 ; D P=0,41)$. $O$ teste $t$ independente revelou-se significativo, ou seja, $[\mathrm{t}(282)=2,47, \mathrm{p}<0,01]$. O intervalo de confiança para as diferenças estimadas das médias populacionais é 0,02 a 0,25 . Apesar da diferença de médias entre os participantes ser pequena $(0,15)$, os resultados confirmaram que, nesse estudo, os idosos estão mais sujeitos a violência que as idosas.

\section{Análise dos pressupostos para a regressão múltipla}

A regressão linear múltipla pode descrever a relação de influência entre uma variável dependente e duas ou mais variáveis independentes. (Tabachnick \& Fidel, 2007). Segundo essas autoras, alguns pressupostos devem ser atendidos para que não ocorram erros tipos I e II na análise dos dados. Um destes pressupostos é a adequação do número de participantes, que deve ser calculado por meio da regra contida na fórmula $\mathrm{N} \geq 50+8 \times \mathrm{M}$ (número de participantes deve ser igual a 50 adicionado a oito vezes o número de variáveis independentes $(M)$, sendo que o nosso estudo possui quatro variáveis. De acordo com a referida fórmula, o número mínimo para aplicação da regressão seria de 82 participantes, já que possui quatro variáveis independentes. Assim, a amostra $(\mathrm{N}=284)$ superou 0 número mínimo exigido para a regressão. No mesmo sentido, a 
amostra atende também aos critérios de Hair et al. (2009), que sugere a proporção de 50 casos por variável independente (em nosso estudo quatro) o que resultaria no total mínimo de 200 participantes, ou seja, o estudo obteve 84 participantes além do mínimo exigido por Hair et al. Finalmente, nenhuma das correlações entre as variáveis foi maior que 0,90, demonstrando a inexistência de multicolinearidade.

\subsection{Análises de regressão múltipla}

Objetivando verificar o poder preditivo das variáveis independentes sobre a variável critério, foi o modelo de regressão múltipla, o qual continha como variável critério a violência e como variáveis preditoras, a renda familiar, o nível de conflitos no relacionamento, sexo e a dependência do idoso. A variável categórica sexo foi transformada em variável dummy ( $0=$ feminino; $1=$ masculino $)$ antes de ser inserida no modelo.

Os resultados da análise de regressão linear múltipla revelou que o modelo foi significativo e explicou $12 \%$ da violência contra o idoso $\left(R^{2}=0,12 ; F=10,24 ; p<0,001\right)$. Inseridas todas as variáveis do estudo no modelo, apenas a variável sexo $(\beta=-0,12 ; \mathrm{t}=-2,12 ; \mathrm{p}<$ $0,05)$ e o nível de conflitos $(\beta=0,29 ; \mathrm{t}=5,14 ; \mathrm{p}<0,001)$ alcançaram significância estatística (Tabela 5). Para os idosos em geral, quanto mais conflitos apontados no relacionamento, maior foi o nível de violência reportado. Os resultados confirmaram, ainda, que a violência tende a ser mais alta contra os homens idosos.

Tabela 5 - Regressão múltipla: violência, conflitos, sexo, renda familiar e dependência.

\begin{tabular}{|c|c|c|c|}
\hline \multicolumn{4}{|c|}{ Violência } \\
\hline $\begin{array}{r}\mathbf{R}^{2}=0.12-\mathbf{F}= \\
10,24 ;\end{array}$ & $\mathbf{p}=0$ & & \\
\hline Variáveis & $\mathrm{B}$ & $t$ & $P$ \\
\hline Nível de conflitos & 0,29 & 5,14 & $0,000 * * *$ \\
\hline Sexo do idoso & $-0,12$ & 2,12 & $0,03 *$ \\
\hline Renda familiar & $-0,09$ & 1,50 & 0,13 \\
\hline Dependência geral & $-0,10$ & 1,70 & 0,08 \\
\hline
\end{tabular}

\section{Discussão}

O presente estudo teve por objetivo investigar os fatores de risco à violência contra os idosos na cidade do Rio de Janeiro. Com base na literatura especializada, foram selecionadas quatro variáveis que poderiam influenciar a violência contra idosos, ou seja: nível de 
conflitos no relacionamento, dependência do idoso, sexo do idoso e renda familiar. Seus resultados são discutidos a seguir.

Dentre uma amostra setorizada de pessoas que sofrem ou não de violência no Rio de Janeiro (ou seja retirando-se deste cálculo os idosos que estavam denunciando atos de violência contra eles próprios na Delegacia de Idosos Copacabana, e que, portanto, sabidamente haviam sofrido violência, o percentual de idosos cariocas que sofrem violência alcançou $16,7 \%$, como apontado na seção dos resultados. Este percentual está próximo ao encontrado pela literatura que ressalta que $12 \%$ dos idosos brasileiros já sofreram violência (Gaioli \& Rodrigues, 2008; Vieira, Jacy, \& Freitas, 2005; Faleiros, 2007).

O nível de conflitos foi confirmado como preditor da discriminação contra o idoso. Este resultado corroborou os estudos de Alves (2004), que apontou os conflitos conjugais e familiares como fatores de risco à violência contra idosos. Outros autores elegem o relacionamento conflituoso com familiares como preditor da violência contra o idoso (Cooney, 1995; Faleiros, 2006; Hirsch \& Loewy, 2001).

Nesta amostra, a dependência do idoso não foi considerada preditora de violência. Esse resultado corrobora os estudos de Cooney (1995) e Paveza (1992), que atribuíram pouca relevância da dependência do idoso enquanto preditor de violência. Contudo, os resultados não corroboram os estudos de Hirsch e Loewy (2001) e Gonçalves (2006), que consideram a dependência do idoso um fator de risco à violência contra este. No mesmo diapasão, Laks, Werner e Jr (2006) entendem como fatores de risco a debilidade física e cognitiva dos idosos.

Da mesma forma, não houve predição da renda familiar com relação à violência contra o idoso. Esse resultado corrobora as deduções de Alencar (2005); Day et al. (2003); Debert e Oliveira (2007) e Menezes (1999) que sustentaram a irrelevância da condição econômica em relação à violência contra o idoso. Diante das abordagens ainda ambivalentes da literatura sobre este tema, é preciso ressaltar a relevância de novas pesquisas para confirmar se a dependência física, cognitiva e financeira se correlaciona ou não com as atitudes de violência em outros grupos de idosos.

Quanto ao gênero, o teste $t$ demonstrou que os homens mais velhos estão mais sujeitos as atitudes de violência que as mulheres mais velhas. A regressão linear múltipla confirmou este resultado e corroborou com Mascarenhas et al. (2013) e com Gaioli e Rodrigues (2008) que constataram a prevalência de vítimas idosas do sexo masculino $(58,6 \%)$. Por outro lado, os resultados não corroboram as inferências de Aitken e Griffin (1996); Sanches, Lebrão e Duarte (2008); e Sinhoretto (2000) que sustentam que as mulheres idosas sofrem mais violência que os homens idosos. Esta divergência de 
resultados revelam a necessidade da realização de outras pesquisas que confirmem as vitimas e os agressores por sexo.

Diante das ambivalências existentes das variáveis dependentes e a violência, Sousa et al (2010) ressaltam a necessidade de futuras produções científicas que contribuam para o maior entendimento e desencadeamento de novas pesquisas acerca do assunto. Apesar da violência não ser um fato social tão novo no mundo, diante do aumento do numero de idosos existentes e da escassez de recursos para atendimento de necessidades de varias faixas etárias, torna-se cada vez mais urgente o cuidado intergeracional (França, 2012) bem como a contemplação de medidas voltadas à prevenção, autuação e condutas adequadas, tanto por parte de órgãos e profissionais, sejam ou não da área da saúde e quanto aos próprios idosos que necessitam de atendimento com respaldo de orientação.

Outro aspecto a ser ressaltado foi a não notificação da violência sofrida pelos idosos. Nesse diapasão, os resultados revelam que, de um total de 127 idosos agredidos, 29 deixaram de queixar-se e 98 agredidos informaram as agressões sofridas às autoridades (aqueles da Delegacia de Copacabana). Tais resultados representam uma subnotificação de $22,8 \%$ se considerados a amostra total de 284 idosos e 127 agredidos. Este resultado nos remete às conclusões de Silva e França (2013), que apontam uma tendência dos idosos a não denunciarem seus agressores e Faleiros (2007) que ressalta a tendência desta não denúncia principalmente no caso da violência intrafamiliar (Cooney, 1995; Faleiros, 2006; Hirsch \& Loewy, 2001). Alencar (2005) atribui algumas razões para essa omissão de denúncia: carência de locais para registro, a falta de importância dada a esse tipo de violência ou mesmo pelo conceito de violência dominante na população, que se restringe apenas à violência física ou à morte. Já, Grossi e Souza (2003) acreditam que a subnotificação ocorre porque, em sua maioria, os idosos temem por si próprios ou zelam por suas famílias, deixando assim de procurar ajuda. Independente do motivo alegado pelas vítimas, Espíndola e Blay (2007) salientam que a subnotificação dificulta a identificação de vítimas e agressores. De fato, se não se identifica nem os agressores nem as vítimas, cria-se o que Duarte et al. (2011) denominou de "cifra obscura", "cifra negra" ou "delinquência oculta", de modo a estabelecer uma divergência entre a parcela de agressões formalmente registrada e a parcela invisível. São necessários estudos mais profundos acerca da subnotificação, fato de extrema relevância, notadamente como ferramenta de combate à violência contra as pessoas idosas.

No tocante ainda a subnotificação, vale assinalar que novas pesquisas tipo survey sobre esta questão precisam ser realizadas, devendo ser priorizada a representatividade geográfica da população da cidade do Rio de Janeiro e de outras cidades que precisam ser investigadas. 
Outra sugestão seria, por meio da abordagem qualitativa, realizar grupos focais com idosos agredidos e que denunciam e com os que não denunciam para saber os motivos da subnotificação, como por exemplo se a maioria está relacionada à questões intrafamiliares.

Quanto ao tipo de violência predominante, os resultados demonstraram maior incidência da violência psicológica em relação aos outros tipos de violência: financeira, física e mista. Aliás, todos os tipos de violência podem redundar em sequelas psicológicas e morais que tendem a se perpetuar por longo tempo (Oliveira, Gomes e Amaral, 2012).

\section{Considerações finais}

A presente pesquisa teve por objetivo apresentar os fatores que influenciam a violência contra o idoso, sendo testadas quatro variáveis: nível de conflitos percebidos pelos idosos, renda familiar, sexo e a dependência do idoso. Os resultados apontaram para maior incidência da violência psicológica (76\%) em relação aos outros tipos de violência. Houve correlação significativa da violência com todas variáveis independentes do estudo: o nível de conflitos, sexo, renda e dependência do idoso. Contudo, apenas o nível de conflitos e o sexo predisseram a violência contra o idoso.

Uma das limitações deste estudo foi que os resultados são específicos de uma amostra de conveniência no Rio de Janeiro, que apesar de numericamente robusta, precisa ser replicada e expandida em outros locais no Rio de Janeiro. Outra limitação, mas que não fez parte do seu escopo, foi a investigação das consequências da violência, que precisam ser abordadas em futuras pesquisas, dada a sua relevância frente a adoção de medidas preventivas e de apoio às vitimas. Vale assinalar a ausência de um instrumento brasileiro especifico que medisse a violência contra o idoso com uma escala que ofereça gradação mais ampla do que a escala de ageísmo de Palmore (2001) que varia de 1 a 3 . No contexto do trabalho, por exemplo, França et al. (2014) construíram recentemente uma escala para medir as atitudes preconceituosas contra os trabalhadores mais velhos. Tais pesquisas podem resultar em sugestões ou recomendações para reduzir a discriminação e a violência contra os idosos.

É importante reforçar que a violência contra idosos acompanha a humanidade desde seus tempos mais remotos, de modo que perpassa os limites históricos, geográficos, sociais e econômicos. Nesse sentido, Soares (2013) concluiu que o que mais contribuiu para as agressões foi simplesmente a idade da vítima (idosa).

A despersonalização e a visão estereotipada do idoso perante a sociedade levaram a atos de ageísmo e segregação, estes que já se identificam como atos de violência. Quanto aos agressores, esses 
podem estar visíveis e ao lado da vítima, bem como "invisíveis" e difusos pelo tecido social, sendo certo de que ora toma forma de pessoa física, ora se manifesta como o próprio sistema em que está inserido o idoso. A relevância e abrangência da questão deverão servir de combustível para outras pesquisas que precisam ser realizadas acerca da violência, buscando suas formas, números, sujeitos, sociedade, fatores de risco e prevenção. Sobretudo, seria pertinente que a investigação das causas de agressões contra os idosos sob o ponto de vista do agressor.

A relação da violência com os preconceitos contra idosos precisa ser investigada nas abordagens qualitativas e quantitativas, devendo ser estimulada a criação de novos instrumentos de aferição de preconceitos, bem como ferramentas para intervenções e, principalmente, para a prevenção aos riscos de violência. Nesse sentido, a luta contra a discriminação contra idosos deve ser uma questão de saúde pública e contar com esforços de diversos segmentos sociais. Conforme apontado por Castro et al (2013) é necessário priorizar, fiscalizar e implementar as ações preconizadas nas políticas públicas direcionadas aos idosos. Teles (2013) ressalta que a participação de todos nas esferas de decisão política poderá significar, em breve, o diferencial no tratamento dado as situações que violam os direitos das pessoas idosas no Brasil, como a violência. Oliveira, Leite, Monteiro e Pavarine (2012) assinalam ainda que o Estatuto do Idoso foi um marco legal nas políticas publicas e contribuiu para o aumento da consciência e informação sobre a violência contra os idosos.

Por fim, como argumentado por França (2012), a mídia tem papel fundamental em relação à quebra de preconceitos e a discriminação contra pessoas idosas. Apesar de os meios de comunicação estarem mais atentos à discriminação contra mulheres, negros e homossexuais, ainda são raras as menções frente à discriminação contra idosos. Pesquisas nesse sentido poderão servir como exortadores no processo de mudança social na direção do respeito, cidadania, participação social e prevenção contra os vários tipos de violência perpetrada contra idosos.

\section{Referências}

Alencar, R. S. (2005). Punidos por envelhecer. Estudos interdisciplinares envelhecimento, 8, 67-81.

Alves, J. F. (2004). Factores de risco e indicadores de abuso e negligência de idosos. Polícia e Justiça, 133-151. Recuperado em 09 de novembro, 2014, de: http://repositorium.sdum.uminho.pt/handle/1822/4423?mode= full\&submit_simple=Mostrar+registo+em+formato+completo 
Aitken L, \& Griffin G. (1996). Gender issues in elder abuse. London, Sage.

Araujo, L. F., \& Lobo Filho, J. G. (2009). Análise psicossocial da violência contra idosos. Psicologia: Reflexão e Crítica, 22(1), 153-160. Recuperado em 09 de novembro, 2014, de: http://www.scielo.br/pdf/prc/v22n1/20.pdf

Aronson, E., Wilson, T. D., \& Akert, R. M. (2002). Psicologia social (Trad R. Jungmann). Rio de Janeiro: LTC.

Beauvoir, S. (1990) A velhice. Rio de Janeiro: Nova Fronteira

Carneiro, V. L., \& França, L. H. F. P (2011). Conflitos no relacionamento entre cuidadores e idosos: o olhar do cuidador. Revista. Brasileira. Geriatria Gerontologia, 14(4), 647-641. Recuperado em 14 de novembro, 2014, de: http://revista.unati.uerj.br/scielo.php?script=sci_arttext\&pid=S 1809-98232011000400005\&lng $=$ pt\&nrm $=$ iso

Carolino, J. A., Cavalcanti, P. B., \& Soares, M. L (2010). Vulnerabilidade Social da População Idosa e a Necessidade de Políticas de Proteção como Mecanismo de Inclusão Social. Qualit@s Revista Eletrônica. 9(1), 1-18. Acessado em 18/11/2014. Disponível em http://revista.uepb.edu.br/index.php/qualitas/article/viewArticl e/587

Castro, A. P. , Guillam, M. C. R., Souza, E. S. S., \& Marcondes, W. B. (2013). Violência na velhice: abordagens em periódicos nacionais indexados. Ciência e Saúde Coletiva, 18(5), 12831292, Recuperado em 14 de março, 2015, de: http://dx.doi.org/10.1590/S1413-81232013000500013

Cooney, C., \& Mortimer, A. (1995) Elder abuse and dementia: a pilot study. International Journal of Social Psychiatry, 41(4), 276283.

Couto, M. C. P. (2005). Fatores de Risco e de Proteção na Promoção de Resiliência no Envelhecimento. Dissertação de Mestrado, Universidade Federal do Rio Grande do Sul, Porto Alegre, RS, Brasil.

Couto, M. C. P. P., Koller, H. S., Novo, R., \& Soares, P. S. (2009). Avaliação de Discriminação contra Idosos em Contexto Brasileiro. Psicologia: Teoria e Pesquisa, 25(4), 509-518.

Day, V. P., Telles, L. E. B., Zoratto, P. H., Azambuja, M. R. F., Machado, D. A., Silveira, M.B, \& Blank, P. (2003). Violência doméstica e suas diferentes Manifestações. Revista de Psiquiatria do Rio Grande do Sul, 25(1), 9-21.

Debert, G. G., \& Oliveira, A. M. (2007). A polícia e as formas de feminização da violência contra 0 idoso. São Paulo em Perspectiva, 21(2), 15-28. 
Debert G. G. (2004). A reinvenção da velhice: socialização e processos de reprivatização do envelhecimento, São Paulo: Edusp.

Duarte, M. C. A., Silva, C. A., Costa, R. S. Cangerana, D. S., \& Gonçalves, S. L. (2011). Crianças, mulheres e idosos: um estudo sobre vítimas invisíveis, Pró Ciência: Centro Universitário Moacyr Sreder Bastos, 1 (1), 42-74.

Espíndola, C.R., \& Blay, S. L. (2007). Prevalência de maus-tratos na terceira idade: revisão sistemática. Revista de Saúde Pública, 41(2), 301-306.

Faleiros, V. P.(2007). Cidadania e direitos da pessoa idosa. Ser Social, (2), 35-61, Recuperado em 14 de Março, 2015, de http://seer.bce.unb.br/index.php/SER_Social/article/view/250/ 1622

Fernandes, M. G. M., \& Assis, J. F. (1999). Maus-tratos contra o idoso: Definições e estratégias para identificar e cuidar. Gerontologia, 7(3), 144-149.

Fernandes, N. F., Afonso, R. M., Pereira, H., \& Loureiro, M. J. (2012). Avaliação da percepção de discriminação em pessoas idosas. International Journal of Developmental and Educational Psychology 108 Infad revista de psicologia, 1(2), 105-114.

Ferreira-Alves, J., \& Novo, R. (2006). Avaliação da discriminação social de pessoas idosas em Portugal. International Journal of Clinical and Health Psychology, 6, 65-77.

Fonseca M.M., \& Gonçalves H.S. (2003). Violência contra o idoso: suportes legais para intervenção, Interação em Psicologia, 7(2), 121-128.

França, L. H. F. P., Silva, A. M. T. B., \& Barreto, M. S. L.(2010). Programas intergeracionais, quão relevantes eles podem ser para a sociedade brasileira? Revista Brasileira de Geriatria e Gerontologia, 13(3), 519-532.Recuperado em 17 de novembro, 2014, de: http://revista.unati.uerj.br/scielo.php?script=sci_arttext\&pid=S 1809-98232010000300017\&lng $=$ pt\&nrm $=$ iso

França, L. H. F. P. (2012). Envelhecimento dos trabalhadores nas organizações: estamos preparados? In L.H. França, \& D. Stepansky (Orgs). Propostas Multidisciplinares para o bemestar na Aposentadoria (pp. 25-52). Rio de Janeiro: FAPERJ.

França, L. H. F. P., Brito, A, Amorim, S., Ekman, N., Silva, F. S, Raybolt, L G, \& Silva, L. A. (2014). (Relatório) Ageismo nas Organizações. FAPERJ, APQ1, 110.830/2013. Rio de Janeiro.

Gaioli, C. C. L. O., \& Rodrigues, R. A. P. (2008) Occurrence of domestic elder abuse, Revista Latino-Americana de Enfermagem, 16(3), 465-70.

Gonçalves, C. A. (2006) Idosos: abuso e violência. Revista Portuguesa de Clinica Geral, 22, 739-745. 
Grossi, P. K. , \& Souza, M. R. (2003), Os idosos e a violência invisibilizada na Família, Revista Virtual Textos \& Contextos, (2), 1-14.

Hair, J. F., Black, W. C., Babin, B. J., Anderson, R. E., \& Tathan, R. L. (2009). Análise multivariada de dados. ( $\left.6^{a} \mathrm{ed}\right)$. Porto Alegre: Bookman.

Hirsch, C., \& Loewy, R. (2001). The management of elder mistreatment: Thephysician's role. Wien Klin Wochenschr. 113(10), 384-92.

Krug, E. G. (2002) Abuso de idosos. (I Relatório Mundial sobre violência e saúde. Organização Mundial da Saúde [OMS] p. 125), Genebra.

Laks, J., Werner, J., \& Jr, L. S. M. S. (2006). Psiquiatria forense e direitos humanos nos polos da vida: crianças, adolescentes e idosos. Revista Brasileira de Psiquiatria, 28(2). Recuperado em 09 de novembro, 2014, de: http://dx.doi.org/10.1590/S151644462006000600006

Lima D. V, Wilbert M. D, Pereira J. M., \& Paulo E. (2012), O Impacto do Fator Previdenciário nos Grandes Números da Previdência Social. Revista de Contabilidade Financeira, 23(59), 128-14.

Mascarenhas, M. D. M., M. D., Andrade, S. S. C. A., Neves, A. C. M., Pedrosa, A. A. G., Silva, M. M. A., \& Malta, D. C. (2012). Violência contra a pessoa idosa: análise das notificações realizadas no setor saúde - Brasil, 2010. Ciência \& Saúde Coletiva, (9) 17, 2331-2341.

Menezes, M. R. (1999). Da Violência Revelada à Violência Silenciada: um estudo etnográfico sobre a violência doméstica contra o idoso. Tese de Doutorado, Universidade de São Paulo: Escola de Enfermagem de Ribeirão Preto, Ribeirão Preto, SP, Brasil.

Micheletti, A. L., Garcia, D., Melicchio, F. , \& Vagostello, L. (2011). Produção cientifica sobre violência nas bases Scielo e LIlacs. Psicólogo Informação, 15(15), 51-68.

Miles, J. N. V., \& Shevlin, M. E. (2001). Applying regression and correlation: A guide for students and researchers. London: Sage Publications).

Minayo, S. M. C. (2003). Violência contra idosos: relevância para um velho problema. Caderno Saúde Pública, 19(3), 783-91.

Minayo, S. M. C., Souza, E. R., \& Paula, D. R. (2010). Revisão sistemática da produção acadêmica brasileira sobre causas externas e violências contra a pessoa idosa. Ciência e Saúde Coletiva, 15(6), 2719-2728.

Mota, A. B.(2013). Violências específicas aos idosos. Sinais Sociais (8) $22,63-85$.

Oliveira, M. L. C., Gomes, A. C. G., \& Amaral, C.P. M. (2012). Características dos idosos vítimas de violência doméstica no 
Distrito Federal. Revista Brasileira de Geriatria Gerontologia, 15(3), 555-566. Recuperado em 14 de Março, 2015, de http://dx.doi.org/10.1590/S1809-98232012000300016

Oliveira, S. C., Leite, A. C., Monteiro, L. C., \& Pavarini, S. C. I. (2012). Violência em idosos após a aprovação do Estatuto do Idoso: revisão integrativa. Revista Eletrônica de Enfermagem, 14(4), 974-982. Recuperado em 09 de novembro, 2014, de: http://www.fen.ufg.br/revista/v14/n4/v14n4a27.htm

Organização Mundial da Saúde [OMS] (2003). Classificação Internacional das Doenças [CID]. Tradução do Centro Colaborador da OMS para a Classificação de Doenças em Português ( $9^{a}$ ed.). São Paulo: EDUSP.

Pagelow, M. D. (1984). Familly violence, New York: Praerger.

Palmore, E.B. (2001). The ageism survey: first findings. The gerontologist, 41, 572-575.

Pasinato, M. T., Camarano, A. A., \& Machado, L. (2006), Idosos vítimas de maus tratos domésticos: estudo exploratório das informações levantadas nos serviços de denúncia. Texto para discussão. (1.200) Rio de janeiro: IPEA.

Pasquali L.(2012). Analise fatorial para pesquisadores. Brasília: LabPAM.

Paveza, G.J. (1992). Severe family violence and Alzheimer's disease: prevalence and risk factors. The Gerontologist, 32, 493-497.

Podnieks, E. (1992). National survey on abuse of the elderly in Canada. Journal of Elder Abuse and Neglect, (4), 5-58.

Riffiotis, T. (2000). O ciclo vital contemplado: A dinâmica dos sistemas etários. In M. L. Barros (Org.). Sociedades negroafricanas em Velhice ou Terceira Idade? Estudos Antropológicos sobre Identidade, Memória e Política (pp.27-35). Rio de Janeiro: Editora FGV.

Sanches, A. P. R. A., Lebrão, M. L., \& Duarte, Y.A.O. (2008). Violência contra o idoso: uma questão nova? Saúde Social, 17(3). Recuperado em 14 de Março, 2015, de: http://dx.doi.org/10.1590/S0104-12902008000300010

Silva, A. E., \& França, L. H. F. P. (2013). Violência e maus tratos contra as pessoas idosas. Sinais Sociais, (8)22, 115-141.

Silva T. (2011). Violência contra a pessoa idosa: do invisível ao visível. Revista Kairós Gerontologia, 14(1), 65-78.

Sinhoretto, J. (2000). Além de mulheres, idosas: um estudo de caso da Delegacia Policial de Proteção ao Idoso de São Paulo. Boletim IBCCRI M, 8, 1-2.

Soares, N. M. F (2013). Envio de cartão não solicitado fere CDC. Jornal A tarde, 8, mês Junho.

Sousa, D. J., White, H., Soares, L. M., Nicolosi, G. T., Cintra, F. A., \& D'Elboux, M. J. (2010). Maus-tratos contra idosos: atualização dos estudos brasileiros. Revista Brasileira de Geriatria e 
Gerontologia, 13(2), 321-328. Recuperado em 14 de Março, 2015, de: http://dx.doi.org/10.1590/S180998232010000200016

Tabachnick, B., \& Fidell, L. (2007). Using multivariate analysis. Needham Heights: Allyn \& Bacon.

Teles, J. L (2010). A Construção das políticas publicas nos espaços democráticos de participação cidadã: a violência contra pessoas idosas na agenda do movimento social. Ciência e Saúde Coletiva, 15(6), 2669-2671.

Torres, C. V., França, L. H. F. P., Oliveira, A., \& Presotti, L. (no prelo). Diagnóstico de Diversidade Cultural e Inclusão nas Organizações. In H. Mendonça, \& M. C. Ferreira (Orgs.) Diagnóstico em organizações: teoria e prática. Casa do Psicólogo / Editora Pearson: São Paulo.

Valadares, F. C., \& Souza, E. R. (2010). Violência contra a pessoa idosa: análise de aspectos da atenção de saúde mental em cinco capitais brasileiras. Ciência e Saúde Coletiva, (15)6, 2763-2774.

Vieira, S., Jacy, A., Freitas, M. C., Almeida, Q. T. (2007). Violência contra os idosos: análise documental. Revista Brasileira de Enfermagem, 60 (3), 268-272.

\section{Endereço para correspondência \\ Edson Alexandre da Silva}

Universidade Salgado de Oliveira

Programa de Pós-Graduação em Psicologia

Rua Marechal Deodoro, 211, Bloco B $2^{\circ}$ Andar, CEP 24030-060, Centro, Niterói RJ, Brasil

Endereço eletrônico: edxandiedson@gmail.com

\section{Lucia Helena de Freitas Pinho França}

Universidade Salgado de Oliveira

Programa de Pós-Graduação em Psicologia

Rua Marechal Deodoro, 211, Bloco B $2^{\circ}$ Andar, CEP 24030-060, Centro, Niterói RJ, Brasil

Endereço eletrônico: luciafranca@luciafranca.com

Recebido em: 01/06/2015

Reformulado em: 23/11/2014

Aceito para publicação em: 05/02/2015

\section{Notas}

* Advogado. Mestre em Psicologia pelo Programa de Pós-Graduação da Universidade Salgado de Oliveira (2013) Niterói - Rio de Janeiro.

** Professora titular do Programa de Pós-Graduação em Psicologia da Universidade Salgado de Oliveira - Universo, Niterói, Rio de Janeiro, Brasil. PhD em Psicologia pela Universidade de Auckland (NZ) em 2004. 